\title{
A New Way with Words: Bringing Qualitative Research Findings to Action
}

\author{
Lindsay Tascona $^{1} \mathbb{D} \cdot$ Katherine Harman $^{2} \cdot$ Sheri Price $^{1}$
}

Accepted: 1 February 2021 / Published online: 2 March 2021

(C) International Association of Medical Science Educators 2021

\begin{abstract}
The use of arts-based knowledge translation (KT) methods such as video remains underutilized in the research arena, despite the strong influence and reach of technology in society. This paper provides a detailed description of the process involved in producing a video as a novel KT strategy to respond to and address findings from our research on professional socialization experiences of physiotherapy students. Specifically, the video challenged dominant stereotypes regarding the profession by depicting the realities and rewards of modern physiotherapy practice. Using a guiding KT framework, this paper provides insight on how researchers can disseminate their study findings in an impactful way using multimedia. Creative outlets such as video and social media are innovative dissemination tools that enable KT to have a powerful and lasting impact.
\end{abstract}

Keywords Knowledge translation $\cdot$ Multimedia $\cdot$ Arts-based $\cdot$ Dissemination $\cdot$ Physiotherapy

Effective knowledge translation (KT) can take many forms and is essential in the process of communicating research findings to target audiences or populations. The Canadian Institutes of Health Research define KT as "a dynamic and iterative process that includes the synthesis, dissemination, exchange and ethically sound application of knowledge to improve health, provide more effective health services and strengthen the health care system" [1]. Researchers often rely on traditional end-of-grant KT methods such as journal publications or presentations at conferences to present their findings [2]. Traditional KT strategies are useful when the knowledge user is familiar with academic journals or attends conferences; however, these methods may be ineffective when translating knowledge to broader audiences [2,3].

Arts-based methods of disseminating qualitative research findings are becoming increasingly popular, as they provide researchers a unique and impactful alternative to reach their target audience [4]. A scoping review by Boydell et al. [5] found that "the most widely used art genre is photography, followed by theatre, with relatively little use of other methods

Lindsay Tascona

lindsay.tascona@dal.ca

1 Dalhousie University, School of Nursing, Halifax, Nova Scotia, Canada

2 Dalhousie University, School of Physiotherapy, Halifax, Nova Scotia, Canada such as poetry, dance and video". Multimedia methods such as video are widely accessible [5-7] and have the potential for enhanced engagement of participants and audiences [8] but are underutilized as a dissemination strategy for KT [9-12]. In addition, and relevant to this study, video dissemination can enable participants' stories to be told in a way that can challenge stereotypes widely held by society [4]. Despite the benefits of this KT method, there is little published about the process of developing a video production for this purpose.

This paper aims to address this gap by providing a detailed account of how a research team exploring professional socialization experiences and interprofessional learning amongst first-year physiotherapy students developed a video production that challenged stereotypes about the profession. First, an overview of the study will be presented, including a description of professional socialization and the study findings. Then, the video production process is described in-depth, highlighting the valuable knowledge gained from the experience, challenges that arose and the impact the video had within a larger social context.

\section{Background}

Our study explored the process of professional identity development and the evolution and views of interprofessional practice of physiotherapy students in the first year of their 
program [13]. This study was part of a larger longitudinal narrative inquiry exploring professional socialization experiences of students in dentistry, medicine, nursing, pharmacy and physiotherapy programs [13].

Professional socialization refers to the dynamic process of learning the values, characteristics and practice behaviours that are necessary to assume a professional role [14-18]. Typically, this process begins prior to formal education and continues throughout a professional career $[19,20]$. Professional socialization influences and is influenced by stereotypical expectations, assumptions and norms with regard to the role, identity and social behaviours of a profession [14, 15, 19, 21-23]. This is particularly relevant in the health professions, as Price et al. [24 p. 103] highlight: "students interested in a health professional career are often socialized to consider the contributions of one profession over another, which often perpetuates historical hierarchies and can impede collaborative teamwork". Developing a greater understanding of the social context of professional socialization can enhance interprofessional education (IPE) by promoting collaboration amongst health professional students and supporting professional identity development [13, 14, 24-29].

Our research sought to understand the career choice and professional socialization experiences of physiotherapy students from pre-entry to the end of the first year of study. Details of methods and findings can be found in our published manuscript [13].

The key findings from our study suggested that the stereotypic views of physiotherapy practice (e.g. mostly working with people with orthopaedic conditions or athletes) held by prospective physiotherapy students led to role uncertainty and confusion during their first term of study. We concluded that this narrow understanding of the scope of physiotherapy practice is a disservice to the profession. After publishing our findings for our academic colleagues, we produced a video to challenge the stereotypes of physiotherapy practice in a way that could reach future candidates of the profession, other healthcare professional students and the general public.

\section{KT Innovation}

The increasing prevalence of arts-based dissemination strategies is driving an important shift from traditional methods and requiring researchers to consider new ways to effectively share research findings to target audiences. However, there currently remains a gap in the literature informing researchers about how to translate their research findings into a dynamic multimedia production. This section of the article will discuss the rationale behind choosing video as a dissemination tool, the process of developing a video production, the challenges that arose and the impact that the video had within a larger social context.

\section{Rationale}

Though choosing a dissemination tool for end-of-grant KT can be a time-consuming process, we used guidelines for knowledge dissemination Jacobson [30] and Gagnon [31] and considered: what was our message, who was our audience, how we would reach them and when, what they needed to know, how would our message be packaged and delivered and what we hoped to achieve by sharing our message. Answering these questions led us to decide to create a video production. Because our principal target audience was prospective physiotherapy students, we favoured a dynamic and accessible KT method compared with a traditional one. Moreover, choosing to use video as a medium enabled us to bring our research findings to life by creating a story about the physiotherapy profession that audiences could connect with. In order to ensure our digital dissemination method remained evidence-informed and scholarly, while creating the video we followed the recommendations of Gagnon [31]. The guiding framework includes five components to consider when utilizing any dissemination tool: (1) the message, (2) the audience, (3) the messenger, (4) the method and (5) the outcome [31]:

1. Message - the message should be informed by evidence. The message that we wanted to convey was that the physiotherapy scope of practice is much broader than the narrow concept described by participants in our study "as a profession with strong ties to athleticism, physical fitness and clients with musculoskeletal injuries".

2. Audience - the target audience should be identified early in the dissemination process and the message should be formulated in a way that is contextually relevant to knowledge users. Our primary audience was undergraduate-aged students aspiring to become physiotherapists. We also wanted to appeal to the general public as potential consumers of physiotherapy services.

3. The messenger - the sources that are used should be both influential and credible. We used first-person accounts of the scope of practice from both faculty members in a physiotherapy university program and clinicians. To address a finding in our study, ${ }^{1}$ we intentionally included

\footnotetext{
${ }^{1}$ In the first term of the program, many participants were surprised to be learning about physiotherapist working in the acute care setting with critically ill patients
} 
narratives from stakeholders who work in the area of acute care.

4. Method-the manner in which the message is shared should have the audience (knowledge user) in mind. It is important to consider how and when a knowledge user would want to be provided with the information. We chose to create a video that was short and exciting, in a format that could be loaded onto the university website (where prospective students search for information about the program), on social media platforms or easily embedded into presentations.

5. Outcome-prior to disseminating knowledge using a specific strategy, it is important to consider the desired outcome of the exercise and develop a method to evaluate its impact. Our desired outcome was to increase the awareness of the breadth of the scope of physiotherapy practice to prospective students. In order to measure its impact, we plan to conduct a survey for incoming physiotherapy students in September 2021.

\section{Video Production Process}

Significant initial groundwork was required before filming could begin. During the early phases of the planning process, our team identified our target audience and the message we wanted to convey. This required a team to plan the information gathering (interviews and images) and determine the conceptual idea of the film that would most effectively portray our message. Although the target audience was originally prospective physiotherapy students, it became apparent throughout the filmmaking process that health care students and professionals were also important targets as our message also highlighted the positive impact of interprofessional collaboration in the healthcare system, the aim of our larger program of research.

To refine our message, we selected the dominant stereotypes and misconceptions revealed in our study. The primary messages were that physiotherapy practice is much more than helping people with sports injuries, and physiotherapists practice in many clinical settings with people who have a wide range of conditions. The next step was to create a list of physiotherapy practice areas or roles that exemplified this wide scope of practice. With that list, we recruited faculty and clinicians who were practicing, teaching or conducting research in those areas. We intentionally recruited a faculty member and a clinician who worked in the area of in-hospital acute care, the area of practice that our study participants reported being unaware of. Drawing on our university and clinical networks, we brought together ten individuals who agreed to a videorecorded interview and informed consent was acquired. The decision to include actual practitioners/faculty members rather than actors was rewarding, as they shared authentic stories, using their own words to describe their practice and afforded us the privilege of filming them on site in their practice settings. These included private practices where owners needed to approve of our presence and sometimes change patient schedules or film after hours, and two different universities and hospitals where administrative approval was required, with additional patient consent when they were filmed.

As we refined our key messages and started recruiting participants, we hired a video production company. Although not always necessary, the company provided high-quality equipment that we did not have ready access to, assisted in co-writing the "scripts" and helped to plan the filming. We had several meetings with the film crew, and this proved valuable as they were not knowledgeable about physiotherapy, yet would be conducting the interviews. Meetings helped to clarify the purpose and intended outcome of the project. Once the planning phase was complete, the filming took roughly four full days.

The company did two types of filming, background filming (BRoll) and interviews. The BRoll enhanced the authenticity of the narratives by displaying the clinical settings and patient interactions with the physiotherapist. The greatest portion of the filming was spent on individual interviews with physiotherapists. The interviews were conducted by the production company staff. Although the interviewer was excellent at putting the interviewees at ease, their lack of knowledge of physiotherapy/health professions led to longer interviews and at times they were not able to capture the context of the participant's story. For this reason, members of the research team were present for all the interviews. This intervention was helpful to identify powerful and impactful quotes and also helped ensure that the core message of the video was adequately captured. In addition, by being present for all the interviews, when it came time to compile short clips of the interviews, it was much easier for the researchers to find sections that they wished to include in the film. Another benefit of being present for the interviews was that we were able to identify the missing content and, as a result, recruited two additional interviewees to fill in some parts of the message that had not yet been captured.

Once the filming process was completed, the company edited the video footage by going through all the content and pulling out elements that they believed were quality pieces of video for the co-investigators to review. Throughout this process, the production company collaborated with the co-investigators enabling them to manipulate and control the message. This process took several weeks. After numerous iterations, involving several hours of reviewing video, the production company produced a 3-min and 41-s video with music and added text (Physiotherapy: Endless Possibilities) https://youtu.be/A0ZaqW3NBiI targeting 
Table 1 Video Production Process

Preliminary Planning

1. Identify key implications and messages from research findings - which was the need to challenge stereotypical and narrow views of physiotherapy practice and represent the breadth and full scope of contemporary physiotherapy practice.

2. Determine target audience (prospective physiotherapy students) and choose medium to convey new messages (video/vignettes).

Video Production Planning

3.Determine key messages to be conveyed and who would serve as "actors". To enhance the authenticity, we chose a varied group of real practitioners.

4. Explore video production companies- Pitch the idea, review quotes and hire team.

5. Develop a loose script of interview questions to elicit key messages.

6.Work with video production company to revise interviews; choose film locations and decide on key background footage.

Filming

7. Film background footage (b-roll) to provide additional context to the video and interviews.

8. Film interviews with members of the research team present to ensure the core message and content were captured in a way that was responsive to our goal.

Note: The length of time for all filming to be completed was approximately 3 days.

Editing

9. Production team edited interview content and identified quality content for the research team to review.

10. Research team reviewed raw content and chose key messages and content for final inclusion. Including b-roll and music.

11. Production company produced a final video approved by our research team that portrayed physiotherapy in a new light.

Note: The entire length of time for the production, from preliminary planning to the final video, was approximately 4 months.

the current stereotypes held regarding the profession and portraying it in a new inspirational light.

\section{Challenges}

As with any end-of-grant KTs, there were challenges that arose throughout the video production process. The time frame it took to complete the entire video from the planning phase to the editing phase was about 4 months. As mentioned, because the videographers were unfamiliar with the realities of physiotherapy and healthcare practice, this resulted in longer interview sessions, extended footage and time-consuming editing. The presence and active participation of our research team at every interview and BRoll filming location mitigated this challenge.

The time commitment is an important consideration in choosing this KT method. Additional time constraints included the timeframe of the grant funding and competing teaching and research demands of the co-investigators. Despite these challenges, the finished product exceeded our expectations in terms of quality and impact. We believe the video is responsive to our research findings in that it portrays a modernized view of physiotherapy practice and instills a sense of unity and pride within the profession.

\section{Social Impact}

It is difficult to measure the impact of the video on viewers; however, within a social context, the video had a strong impact on those who participated in its production. The physiotherapists included in the video felt a strong sense of pride as it depicted the breadth of the scope of their profession and practice. This unexpected impact was valuable and attests to the fact that the individuals included in the video were not actors-they were practitioners and faculty sharing their story, challenging the current stereotypes and creating a modernized narrative of the profession. Moreover, physiotherapy students that were shown this video experienced the same sense of pride in the profession. By carefully considering a new method to disseminate our research findings, our team was able to produce a video that portrays the broad scope of physiotherapy practice, challenging current beliefs held by society. A multimedia platform enabled the profession to be portrayed in a new inspirational light to audiences, demonstrating the impact that imagery can have when used to shape new narratives. Research has revealed that public awareness of physiotherapy in the UK is poor, and those authors called for new methods of informing the public about the profession [32]. And in 2018, Zadro [33] argued that we need to promote physiotherapy using information based on research findings. We found the video format adaptable and easily shared. At the date of manuscript submission, the video has received over 29,000 views on Facebook and over 2000 views on YouTube. At Dalhousie, the video is housed on the School of Physiotherapy website, home page-under the section for prospective students/admissions. The video is also displayed on monitors at Faculty of Health and during 
School of Physiotherapy public awareness and promotional events. The video has been linked to the Faculty and School Newsletters and is routinely shown during orientation week for entering physiotherapy students. Two short "teaser" videos (created in iMovie and Wibbitz) were developed in-house for the purpose of promoting the video on social media where it was used to raise awareness during World Physiotherapy Day and National Physiotherapy Month.

The number of views the video has had demonstrates the power that multimedia productions can have in reaching diverse audiences. However, in order to measure the true impact that this video has had on challenging the widely held views about physiotherapy practice, further research is warranted. In September 2021, our research team will be conducting a survey to incoming physiotherapy students to measure their understanding and views of physiotherapy practice. This research will enable our research team to measure the impact that this KT strategy had in effectively disseminating our findings.

Researchers are regularly given opportunities to disseminate their research findings to various audiences; however, these findings run the risk of not being retained by knowledge users. Daily, individuals are faced with unlimited stimuli competing for one's attention, calling researchers to challenge their current methods of dissemination. By challenging traditional methods of dissemination, and considering new creative outlets, there lies an opportunity to translate knowledge to audiences in a lasting manner that can challenge current beliefs and impact social change.

\section{Conclusion}

As KT methods continue to evolve, and given its regular use in day-to-day life, multimedia platforms such as video are underutilized in the dissemination of research findings. This article provides a detailed account of how this research team studying identity development in physiotherapy students created a video portraying a modernized story of an inspirational profession. The power of multimedia enables research findings to be brought to life by conveying powerful messages that cannot be replicated by traditional written methods. The current COVID-19 pandemic is exemplary, as the media has portrayed health professions in a different light, labelling some as "heroes" while certain professions remain in the shadows. The impact that visual creative outlets such as video can have within society cannot be ignored, calling researchers to challenge their current KT practices to translate their findings in a way that can impact lasting change.
Author Contributions Sheri Price proposed the development of this manuscript. Lindsay Tascona interviewed Sheri Price and Katherine Harman to develop the first draft of the manuscript. All authors reviewed and revised previous versions of the manuscript and approved this final draft.

\section{Declarations}

Ethics Approval This original article does not require ethical approval as it describes the knowledge translation process of a previous study conducted by the authors, in which data was properly anonymized and informed consent was obtained at the time of the original study.

Consent to Participate Informed consent was obtained from all participants that participated in the video's production.

Conflict of Interest The authors declare that they have no conflict of interest.

\section{References}

1. Canadian Institutes of Health Research. Knowledge translation. CIHR (2016). (Available from: https://cihr-irsc.gc.ca/e/29418. html\#2, Accessed 9 June 2020).

2. Graham I, Tetroe J, Gagnon, M. Knowledge dissemination: end of grant knowledge translation. In: Straus S, Tetroe J, Graham I, editors. Knowledge Translation in Health Care: Moving from Evidence to Practice. 2nd ed. West Sussex; John Wiley \& Sons; 2013, p. 75-76.

3. Graham I, Tetroe J. CIHR Research: how to translate health research knowledge into effective healthcare action. Healthc Q. 2007;10:20-2. https://doi.org/10.12927/hcq.18919.

4. Miller Scarnato J. The value of digital video data for qualitative social work research: a narrative review. QualSoc Work. 2019. https://doi.org/10.1177/1473325017735885.

5. Boydell K, Gladstone BM, Volpe T, Allemang B, Stasiulis E. The production and dissemination of knowledge: a scoping review of arts-based health research. Sozialforschung/ Forum: Qualitative Social Research. 2012. https://doi.org/10.17169/fqs-13.1.1711.

6. Keen S, Todres L. Strategies for disseminating qualitative research findings: three exemplars. Forum Qual Sozialforsch. 2007;8(3):17.

7. Colantonio A, Kontos PC, Gilbert JE, Rossiter K, Gray J, Keightley ML. After the crash: research-based theater for knowledge transfer. J ContinEduc Health Prof. 2008;28:180-5. https://doi.org/10.1002/chp.177.

8. Levin T, Scott BM, Borders B, Hart K, Lee J, Decanini A. Aphasia talks: photography as a means of communication, self-expression, and empowerment in persons with aphasia. Top Stroke Rehabil. 2007;14:72-84. https://doi.org/10.1310/tsr1401-72.

9. Dobbins M, Hanna SE, Ciliska D, Manske S, Cameron R, Mercer $\mathrm{SL}$, et al. A randomized controlled trial evaluating the impact of knowledge translation and exchange strategies. Implement Sci 2009;4. https://doi.org/10.1186/1748-5908-4-61.

10. Grimshaw JM, Eccles MP, Lavis JN, Hill SJ, Squires JE. Knowledge translation of research findings. Implement Sci 2012;7. https://doi.org/10.1186/1748-5908-7-50.

11. Lohan M, Aventin Á, Oliffe JL, Han CS, Bottorff JL. Knowledge translation in men's health research: development and delivery of content for use online. J Med Internet Res. 2015;17(1):e31. https://doi.org/10.2196/jmir.3881.

12. Di Noia JD, Schwinn TM, Dastur ZA, Schinke SP. The relative efficacy of pamphlets, CD-ROM, and the Internet for 
disseminating adolescent drug abuse prevention programs: an exploratory study. Prev Med 2003;37:646-53. https://doi. org/10.1016/j.ypmed.2003.09.009.

13. Harman K, Sim M, Lebrun J, Almost J, Andrews C, Davies H, et al. Physiotherapy: an active, transformational, and authentic career choice. Physiother Theory Pract 2019:1-14. https://doi. org/10.1080/09593985.2019.1639230.

14. Price SL, Sim M, Little V, Almost J, Andrews C, Davies H, et al. Pre-entry perceptions of students entering five health professions: implications for interprofessional education and collaboration. $\mathrm{J}$ Interprof Care. 2019:1-9. https://doi.org/10.1080/13561820. 2019.1702514.

15. Day RA, Field PA, Campbell IE, Reutter L. Students' evolving beliefs about nursing: from entry to graduation in a four-year baccalaureate programme. Nurse Educ Today. 2005;25:636-43. https://doi.org/10.1016/j.nedt.2005.09.003.

16. Davis F. Professional socialization as subjective experience: the process of doctrinal conversion among student nurses. Institutions and the Person. 1968:235-51.

17. Dorcy KS. Built space and the socialization of nursing students. West J Nurs Res. 1992;14:632-44. https://doi.org/10.1177/ 019394599201400506.

18. Goldenberg D, Iwasiw C. Professional socialisation of nursing students as an outcome of a senior clinical preceptorship experience. Nurse Educ Today. 1993;13(1):3-15.

19. Khalili $\mathrm{H}$. Interprofessional socialization and dual identity development amongst cross-disciplinary students. [dissertation on the internet]. 2013. [cited 2020 June 9]. Available from: https://ir.lib.uwo.ca/cgi/viewcontent.cgi?article $=3120 \&$ context=etd

20. Miller SE. A conceptual framework for the professional socialization of social workers. J Hum Behav Soc Environ. 2010;20:924-38. https://doi.org/10.1080/10911351003751934.

21. Hean S, Clark JM, Adams K, Humphris D. Will opposites attract? Similarities and differences in students perceptions of the stereotype profiles of other health and social care professional groups. J Interprof Care 2006;20:162-81. https:// doi.org/10.1080/13561820600646546.

22. Reeves S, Palaganas J, Zierler B. An updated synthesis of review evidence of interprofessional education. J Allied Health. 2017;46(1):56-61.

23. Reeves S, Pelone F, Harrison R, Goldman J, Zwarenstein M. Interprofessional collaboration to improve professional practice and healthcare outcomes. Cochrane Database Syst Rev 2017(6).
24. Price S, Doucet S, Hall LM. The historical social positioning of nursing and medicine: implications for career choice, early socialization and interprofessional collaboration. J Interprof Care. 2014;28:103-9. https://doi.org/10.3109/13561820.2013.867839.

25. Adams K, Hean S, Sturgis P, Clark JM. Investigating the factors influencing professional identity of first-year health and social care students. Learn Health Soc Care 2006;5:55-68. https://doi. org/10.1111/j.1473-6861.2006.00119.x.

26. Khalili H, Hall J, Deluca S. Historical analysis of professionalism in western societies: implications for interprofessional education and collaborative practice. J Interprof Care. 2014;28:92-7. https:// doi.org/10.3109/13561820.2013.869197.

27. Price S. Future directions for career choice research in nursing: a discussion paper. Int J Nurs Stud. 2009;46(2):268-76.

28. Price S, McGillis Hall L, Angus J, Peter E. The social context of career choice among millennial nurses: implications for interprofessional practice. J Interprof Care. 2013;27(6):509-14. https://doi.org/10.3109/13561820.2013.816660.

29. Reeves S, Xyrichis A, Zwarenstein M. Teamwork, collaboration, coordination, and networking: why we need to distinguish between different types of interprofessional practice. J Interprof Care. 2018;32:1-3. https://doi.org/10.1080/13561820.2017.1400150.

30. Jacobson N, Butterill D, Goering P. Development of a framework for knowledge translation: understanding user context. J Health Serv Res Policy. 2003;8:94-9. https://doi.org/10.1258/ 135581903321466067.

31. Gagnon ML. Moving knowledge to action through dissemination and exchange. J Clin Epidemiol. 2011;64:25-31. https://doi. org/10.1016/j.jclinepi.2009.08.013.

32. Goodwin R, Moffatt F, Hendrick P, Timmons S, Chadborn N, Logan P. First point of contact physiotherapy; a qualitative study. Physiotherapy. 2020. https://doi.org/10.1016/j.physio. 2020.02.003.

33. Zadro JR, O'Keeffe M, Maher CG. Evidence-based physiotherapy needs evidence-based marketing. Br J Sports Med. 2018;53:528 9. https://doi.org/10.1136/bjsports-2018-099749.

Publisher's Note Springer Nature remains neutral with regard to jurisdictional claims in published maps and institutional affiliations. 